\title{
Serological and morphological prognostic factors in patients with interstitial pneumonia with autoimmune features
}

Yuhei Ito ${ }^{1 *}$, Machiko Arita', Shogo Kumagai ${ }^{1}$, Reoto Takei', Maki Noyama', Fumiaki Tokioka', Keisuke Nishimura², Takashi Koyama $^{3}$, Kenji Notohara ${ }^{4}$ and Tadashi Ishida ${ }^{1}$

\begin{abstract}
Background: To identify the prognostic factors for survival in patients with interstitial pneumonia with autoimmune features (IPAF) who meet the serological domain of the IPAF criteria.

Methods: We retrospectively analysed 99 IPAF patients who met the serological domain and were hospitalised at the Respiratory Medicine Unit of Kurashiki Central Hospital from 1999 to 2015. The high-resolution computed tomography findings were usual interstitial pneumonia (UIP; $n=1)$, non-specific interstitial pneumonia (NSIP; $n=63$ ), NSIP with organizing pneumonia (OP) overlap $(n=15)$, and OP $(n=20)$. One patient who had radiological UIP pattern, and met the serological and clinical domains was excluded. The clinical characteristics, radiological findings, administered therapy, and prognosis of the remaining 98 IPAF patients who met the serological and morphological domains were analysed.
\end{abstract}

Results: The median age of the 98 IPAF patients was 68 years, and 41 (41.8\%) of them were men. Twelve (12.2\%) of the 98 IPAF patients developed other characteristics and were diagnosed with connective tissue disease (CTD) later during the median follow-up of 4.5 years. Univariate Cox analysis revealed systemic sclerosis (SSC)-specific and SSc-associated antibodies (ANA nucleolar pattern, ANA centromere pattern, anti-ribonucleoprotein and anti-Scl-70) positive IPAF, radiological NSIP pattern, bronchoalveolar lavage fluid lymphocytes $>15 \%$, and age as significant prognostic factors for survival. Multivariate Cox analysis revealed radiological NSIP pattern (hazard ratio [HR], 4.48; $95 \%$ confidence interval $[\mathrm{Cl}], 1.28-15.77, p=0.02)$ and age $(\mathrm{HR}, 1.07 ; 95 \% \mathrm{Cl}, 1.02-1.11, p=0.01)$ were significantly associated with worse survival.

Conclusions: We confirmed that radiological NSIP pattern and age are poor prognostic factors for the survival of IPAF patients. This study suggested that the autoantibodies that are highly specific for certain connective tissue diseases might be less important for the prognosis of IPAF compared with the radiological-pathological patterns. The relatively high proportion of IPAF patients who developed CTD later suggests the importance of careful observation for evolution to CTD in IPAF.

Keywords: Interstitial lung disease, Collagen vascular disease, Autoimmune disease, Interstitial pneumonia with autoimmune features, Systemic sclerosis

\footnotetext{
*Correspondence: yi14402@gmail.com

'Department of Respiratory Medicine, Kurashiki Central Hospital, Kurashiki,

Japan

Full list of author information is available at the end of the article
}

(c) The Author(s). 2017 Open Access This article is distributed under the terms of the Creative Commons Attribution 4.0 International License (http://creativecommons.org/licenses/by/4.0/), which permits unrestricted use, distribution, and reproduction in any medium, provided you give appropriate credit to the original author(s) and the source, provide a link to the Creative Commons license, and indicate if changes were made. The Creative Commons Public Domain Dedication waiver (http://creativecommons.org/publicdomain/zero/1.0/) applies to the data made available in this article, unless otherwise stated. 


\section{Background}

Many patients with idiopathic interstitial pneumonia (IIP) present clinical features that suggest an underlying autoimmune process but do not meet the established criteria for connective tissue disease (CTD). Interstitial pneumonia with autoimmune features (IPAF) is a term proposed for the condition of such patients.

In IIP patients, survival and prognosis differ according to the histological pattern, baseline pulmonary function, and age [1-4]. However, some questions remain to be addressed. For patients with CTD-associated interstitial lung disease (ILD), the effect of histological pattern on survival is less certain [5-7]. Does the prognosis of IPAF patients differ according to the radiological-pathological pattern? Previous reports suggested that an underlying CTD was important in determining the prognosis of CTD-associated ILD [5]. If IPAF is thought to be a lungdominant variant of CTD or a CTD preceded by interstitial pneumonia, does the prognosis of IPAF patients differ according to the antibodies that are highly specific for certain CTDs?

The aim of this study was to investigate the prognostic survival factors in IPAF patients who satisfied the serological domain of the IPAF criteria. To answer the 2 aforementioned questions, radiological patterns and specific autoantibodies were included in the analyses.

\section{Methods}

\section{Study subjects}

We retrospectively screened the medical records of 1057 patients with interstitial pneumonia who were hospitalised at the Respiratory Medicine Unit of Kurashiki Central Hospital from 1999 to 2015. Of these, 332 patients met the serological domain of the IPAF criteria. We excluded 192 patients due to insufficient data $(n=41)$, complication with malignant disease at first visit $(n=36)$, known causes (CTD, $n=47$; drug, chronic hypersensitivity, pneumonitis, and others, $n=50$ ), acute interstitial pneumonia $(n=12)$, and acute exacerbation at first visit $(n=6)$. CTD was diagnosed when the patients fulfilled the American College of Rheumatology criteria [8-13]. High-resolution computed tomography (HRCT) images were classified as definite usual interstitial pnaumonia (UIP) pattern, possible UIP pattern, or inconsistent with UIP pattern according to the guidelines for idiopathic pulmonary fibrosis (IPF) [14]. Definite UIP and possible UIP pattern were defined as UIP pattern in this study. The cases interpreted as inconsistent with UIP pattern were further classified as nonspecific interstitial pneumonia (NSIP) pattern, NSIP with organizing pneumonia (OP) overlap, or OP pattern according to the American Thoracic Society (ATS)/ European Respiratory Society (ERS) statement of IIP 2013 [15] and IPAF 2015 [16]. HRCT findings of NSIP were defined as basal predominant reticular abnormalities with traction bronchiectasis, peri-bronchovascular extension and subpleural sparing, frequently associated with ground-glass attenuation. HRCT findings of OP were defined as bilateral patchy areas of consolidation with a subpleural and lower lung zone predominance. NSIP with OP was defined as basal predominant consolidation, often peri-diaphragmatic, associated with features of fibrosis. HRCT images of remaining 140 patients were classified as UIP in 42, NSIP in 63, NSIP with OP in 15, OP in 20 patients based on the predominant pattern. Among 42 patients with UIP pattern, only 1 fulfilled the clinical domain (Raynaud's phenomenon); therefore, in this analysis, we excluded this 1 patient who satisfied serological and clinical domains, considering the rarity of this entity, and focused on the remaining 98 patients with IPAF who satisfied serological and morphological domains (Fig. 1). All patients were carefully examined by rheumatologists and the absence of CTD was confirmed. HRCT was performed with $1.0-\mathrm{mm}$ sections. HRCT scans at first visit were randomised and reviewed by 2 expert pulmonologists of 30 years' and 5 years' experience (MA, YI) and one expert radiologist of 24 years' experience (TK). All disagreements were resolved through consensus.

\section{Data collection}

Clinical data were obtained retrospectively from patient records. We evaluated patients' characteristics, pulmonary function tests, bronchoalveolar lavage (BAL), and serological test results. These tests were conducted for all patients within 1 month of the first diagnosis of interstitial pneumonia. Spirometry and the lung's diffusing capacity for carbon monoxide (DLCO) were measured according to the ATS/ERS recommendation as physiological assessments and were examined within 1 month of the first diagnosis of interstitial pneumonia $[17,18]$. Abnormal cell counts in BAL fluid were neutrophils $>3 \%$, lymphocytes $>15 \%$, and eosinophils $>1 \%$ [19]. Response to treatment was evaluated according to the official ATS/ERS/JRS/ALAT Statement of Idiopathic Pulmonary Fibrosis 2011 [14]. Deterioration was defined as a condition in which a $>5-10 \%$ decline in FVC and $>15 \%$ decline in DLCO occurred over 6 or 12 months.

\section{Specific antibodies}

ANA nucleolar pattern, ANA centromere pattern, antiribonucleoprotein, anti-Scl-70, anti-cyclic citrullinated peptide (CCP), anti-Jo1 antibody (Jo1), anti-tRNA synthetase (anti-tRS) antibodies other than anti-Jo1 (ARS other than anti-Jo1), and anti-La (SSB) were included as CTD-specific antibodies. ANA nucleolar pattern, ANA centromere pattern, anti-ribonucleoprotein, and antiScl-70 were defined as systemic sclerosis (SSc)-specific 


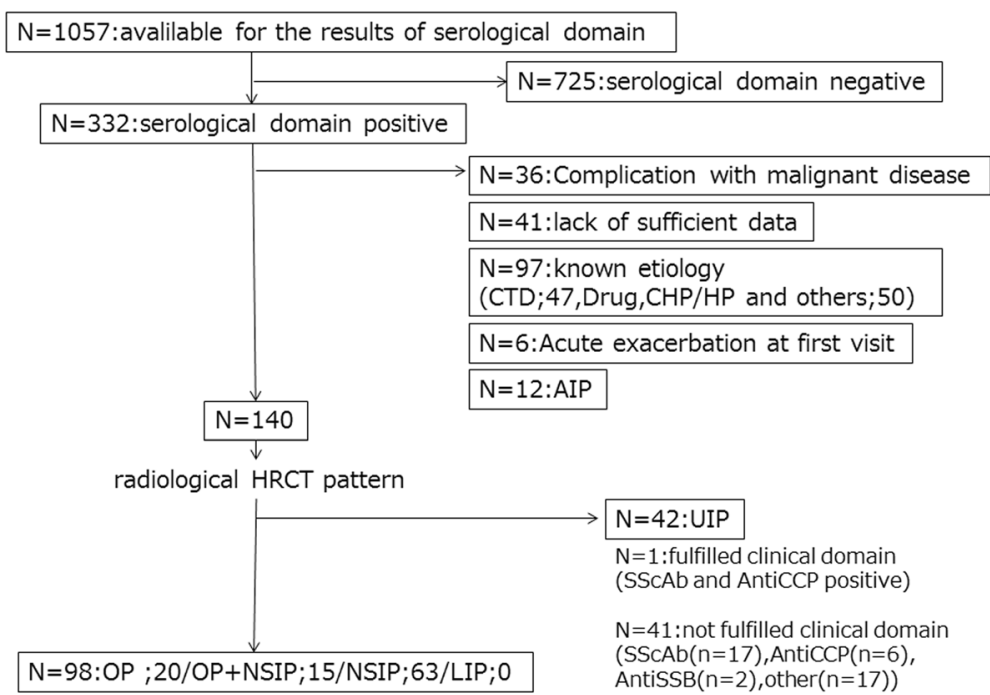

Fig. 1 Flow diagram of selection process for patients with interstitial penumonia with autoimmune features who met the serological domein.

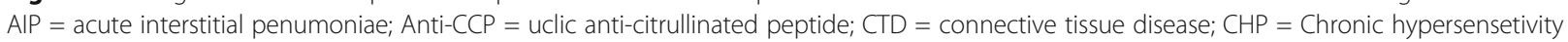
pneumonitis; HP = hypersensetivity pneumonitis; LIP = lymphocytic interstitial pneumonitis; NSIP + OP = NSIP with OP overlap; NSIP = non-specific interstitial pneumonia; OP = organizing penumonia; SScAb = SSc-specidic and SSc-related antibodies; UIP = Usual interstitial pneumonia

and SSc-related antibodies (SScAb). All patients were subdivided into 5 groups, SScAb, anti-CCP, ARS Ab, anti-SSB positive IPAF, and other IPAF, according to the specific antibodies. Seven patients were positive with more than 2 CTD-specific antibodies (SScAb and anti-CCP were present in 1 patient; SScAb and anti-Jo1 in 2; SScAb and anti-SSB in 1; SScAb and anti-SSB in 1; anti-SSB and antiJo1 in 1; and SScAb, anti-SSB, and anti-CCP in 1). These 7 patients and those who tested negative for all specific antibodies were grouped under other IPAF.

\section{Histological assessment}

Among the 98 IPAF patients, 17 underwent surgical lung biopsies (SLB). The major histological patterns were classified according to the current IIPs classification 2013 [15]. Interstitial lymphoid aggregates with germinal centres and diffuse lymphoplasmacytic infiltration were evaluated [16].

\section{Statistical analyses}

Continuous variables are presented as the median and interquartile range. Categorical variables are described as counts and percentages. To detect differences in three groups, we used Kruskal-Wallis test for continuous variables and Steel-Dwass test for post hoc analysis and Fisher's exact test for categorical variables. Survival was evaluated using the Kaplan-Meier survival curves and log-rank test. Cox proportional hazards regression analysis was used to identify significant variables for predicting survival status. Variables selected via the univariate test $(p<0.05)$ were evaluated using multivariate Cox regression analysis. A $p$ value $<0.05$ was considered statistically significant.

\section{Results}

Clinical, radiological, and physiological characteristics of study participants stratified according to HRCT

Of the 98 IPAF patients, 20 (20.4\%) were radiologically classified as OP, 15 (15.3\%) as NSIP + OP, and 63 (64.3\%) as NSIP. The clinical characteristics stratified according to HRCT are shown in Table 1. The proportion of subacute onset was higher in OP and NSIP + OP patterns than in NSIP pattern. BAL fluid data at first presentation were available in 75 (76.5\%) IPAF patients. The percentage of BAL fluid lymphocytes was lower in those with NSIP pattern than in those with OP ( $p=0.001$, Steel-Dwass test) and NSIP + OP patterns ( $p=0.013$, Steel-Dwass test). C-reactive protein (CRP) was higher in those with OP pattern than those with NSIP + OP ( $p=0.004$, Steel-Dwass test) and NSIP pattern ( $p=0.006$, Steel-Dwass test). KL6 was lower in those with OP pattern than in those with NSIP + OP $(p<0.001$, SteelDwass test) and NSIP pattern ( $p<0.001$, Steel-Dwass test).

\section{Therapy and prognosis of study participants stratified according to HRCT}

Therapy and prognosis of study participants stratified according to HRCT patterns are shown in Table 2. Treatment for interstitial pneumonia was introduced in 78 (79.6\%) patients. The 5-year survival rates were $100 \%, 86.7 \%$, and $58.6 \%$ for OP, NSIP + OP, and NSIP, respectively.

HRCT pattern, administered therapy, and prognosis of study participants stratified according to specific antibodies

HRCT patterns stratified according to the specific antibodies are shown in Table 3. The NSIP pattern was relatively common among patients with SScAb and anti- 
Table 1 Clinical, radiographic and physiologic characteristics of study participants stratified by hrct pattern

\begin{tabular}{|c|c|c|c|c|c|}
\hline & & HRCT pattern & & & \\
\hline & total & $\mathrm{OP}$ & $\mathrm{NSIP}+\mathrm{OP}$ & NSIP & $p$ value \\
\hline Number of patients, $\mathrm{n}$ & 98 & $20(20.4 \%)$ & $15(15.3 \%)$ & $63(64.3 \%)$ & \\
\hline Age, yr & $67.5[59.0,76.0]$ & $68.5[64.8,73.8]$ & $67.0[52.5,76.0]$ & $68.0[59.0,76.0]$ & 0.88 \\
\hline Male gender, n (\%) & $41(41.8 \%)$ & $10(50.0 \%)$ & $6(40.0 \%)$ & $25(39.7 \%)$ & 0.693 \\
\hline Smoking & & & & & \\
\hline never smokers, $\mathrm{n}$ & $60(61.2 \%)$ & $12(60 \%)$ & $11(73.3 \%)$ & $37(58.7 \%)$ & 0.653 \\
\hline former/current smoker, $\mathrm{n}$ & $38(38.8 \%)$ & $8(40 \%)$ & $4(26.7 \%)$ & $26(41.3 \%)$ & \\
\hline Onset & & & & & \\
\hline subacute, n (\%) & $36(36.3 \%)$ & $20(100 \%)$ & $14(93.3 \%)$ & $2(3.2 \%)$ & $<0.001$ \\
\hline chronic, n (\%) & $62(63.3 \%)$ & $0(0 \%)$ & $1(6.7 \%)$ & $61(96.8 \%)$ & \\
\hline Laboratory data & & & & & \\
\hline $\mathrm{WBC}, 103 / \mathrm{m} \mathrm{m}^{3}$ & $6900[5725,900]$ & $775[6500,10,325]$ & $8900[6000,9700]$ & $6500[5600,7650]$ & 0.03 \\
\hline $\mathrm{CRP}, \mathrm{g} / \mathrm{dL}$ & $0.46[0.14,1.92]$ & $7.60[3.25,11.59]$ & $1.03[0.50,1.81]$ & $0.25[0.11,0.59]$ & $<0.001$ \\
\hline $\mathrm{KL} 6, \mathrm{U} / \mathrm{ml}$ & $945[552,1673]$ & $321[280,337]$ & $1172[887,3049]$ & $1135[771,1775]$ & $<0.001$ \\
\hline Pulmonary function \%predicted & $n=85$ & $n=11$ & $n=13$ & $n=61$ & \\
\hline FVC, \%predicted & $76.3[62.7,88.6]$ & $81.2[72.1,87.9]$ & $50.9[42.1,65.2]$ & $54.8[46.2,71.9]$ & 0.2 \\
\hline DLCO, \%predicted & $56.6[46.4,76.3]$ & $82.9[75.6,100.6]$ & $67.9[57.1,87.1]$ & $75.6[62.7,88.0]$ & 0.009 \\
\hline BAL fluid & $n=75$ & $n=16$ & $n=12$ & $n=47$ & \\
\hline Lymphocytes, \% & $19.0[10.0,39.0]$ & $53.0[27.5,71.3]$ & $34.9[16.2,48.5]$ & $13.0[8.5,24.1]$ & $<0.001$ \\
\hline Neutrophils, \% & $6.0[1.9,12.5]$ & $7.5[1.8,14.6]$ & $9.7[5.1,16.3]$ & $4.0[1.2,10.5]$ & 0.225 \\
\hline Eosinophils, \% & $1.7[0.9,4.7]$ & $2.0[1.0,12.0]$ & $3.7[1.4,5.0]$ & $1.0[0.3,3.3]$ & 0.177 \\
\hline
\end{tabular}

Autoantibodies, $\mathrm{n}$

\begin{tabular}{|c|c|c|c|c|}
\hline SSC-specific and SSc-reralted antibodies, $\mathrm{n}$ & 36 & 3 & 2 & 31 \\
\hline Nucleolar-ANA, $n$ & 15 & 0 & 0 & 15 \\
\hline Anti-Centromere, $\mathrm{n}$ & 4 & 1 & 0 & 3 \\
\hline Anti-RNP, $\mathrm{n}$ & 9 & 2 & 1 & 6 \\
\hline Anti-Scl-70, n & 8 & 0 & 1 & 7 \\
\hline Anti-CCP, n & 15 & 3 & 2 & 10 \\
\hline Anti-Jo1, n & 9 & 2 & 3 & 4 \\
\hline ARS Ab other than anti-Jo1, $n$ & 4 & 0 & 3 & 1 \\
\hline Anti-La/SSB, n & 7 & 1 & 4 & 3 \\
\hline ANA ( $\geqq 1: 320), n$ & 28 & 1 & 4 & 23 \\
\hline Rheumatoid factor (>60 IU/ml), n & 28 & 8 & 3 & 17 \\
\hline Anti-Ro/SSA, n & 18 & 6 & 3 & 9 \\
\hline Anti-dsDNA, n & 6 & 1 & 2 & 3 \\
\hline Anri-Sm, n & 4 & 1 & 0 & 3 \\
\hline
\end{tabular}

Some patients had multiple serological tests. Data are presented as No. (\%), median(range). ANA antinuclear antibody, Anti-CCP uclic anti-citrullinated peptide, Anti-dsDNA anti-double stranded DNA, Anti-RNP anti ribonucleoprotein, ARS Ab anti-tRNA synthetase antibodies, Anti-Scl-70 anti-Sclero 70, BAL bronchoalveolar lavage, CRP C reactive protein, DLCO diffusing capacity of the lung for carbon monoxide, FVC forced vital capacity, IPAF Interstitial pneumonia with autoimmune features, NSIP non-specific interstitial pneumonia, NSIP + OP NSIP with OP overlap, OP organizing penumonia, SScAb SSc-related antibody

CCP-positive IPAF. The 5-year survival rates were $42.1 \%, 66.7 \%, 75.8 \%, 100.0 \%$, and $75.8 \%$ in SScAbpositive, anti-CCP-positive, ARS Ab-positive, Anti-SSBpositive, and other IPAF, respectively.

\section{Survival and prognostic factors}

Twenty-seven patients (27.6\%) died during the median follow-up period of 4.58 years. The causes of death were documented as respiratory failure $(n=15)$, lung cancer 
Table 2 Therapy and prognosis of study participants stratified by HRCT pattern

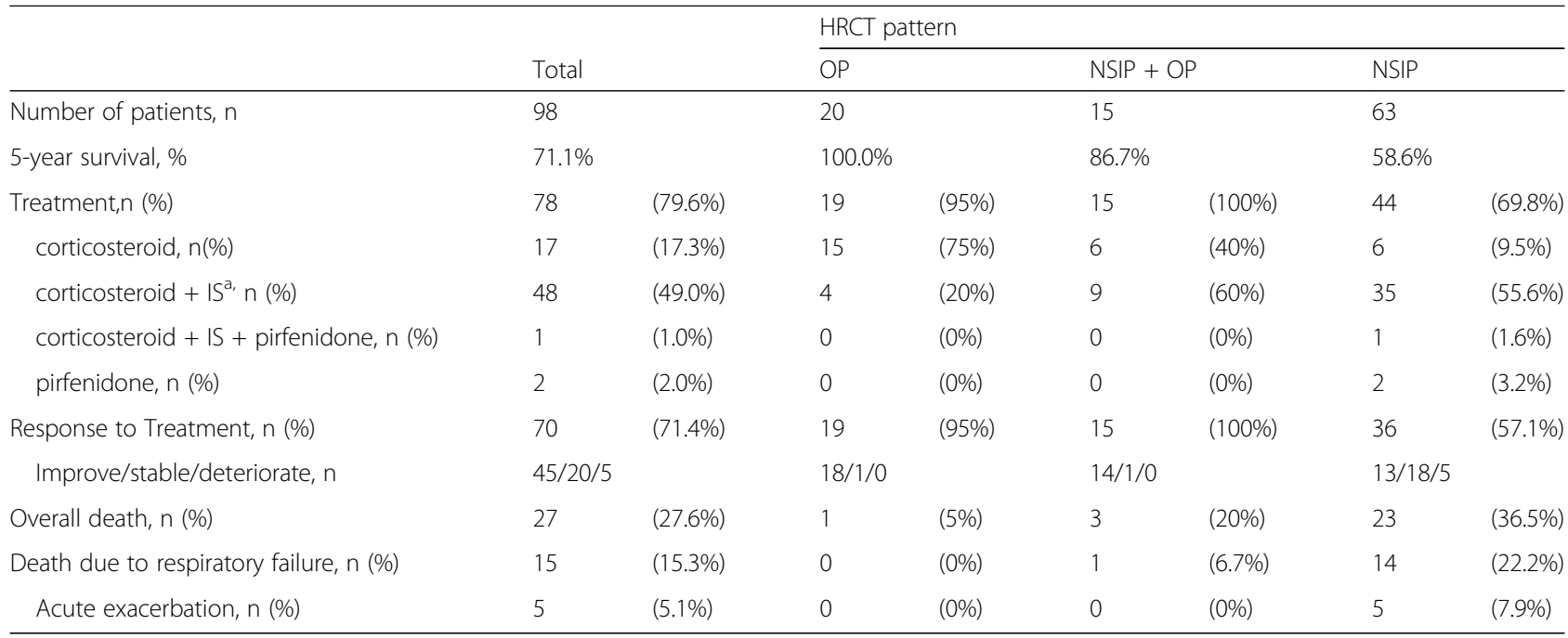

Data are presented as No. (\%). NSIP non-specific interstitial pneumonia, NSIP + OP NSIP with OP overlap, OP organizing penumonia. ${ }^{\mathrm{a}} \mathrm{IS}=$ immnuno suppressants other than corticosteroid which included azathioprine, cyclsporin, cyclophosphamide and tacrolimus

$(n=3)$, other malignant disease $(n=3)$, severe infection $(n=2)$, acute myocardial infarction $(n=1)$, gastrointestinal perforation $(n=1)$, and unknown $(n=2)$. Five patients died due to acute exacerbation amoung 15 patients who died due to respiratory failure. In patients with IPAF, the 5-year survival was $71.1 \%$ and median survival time was 12.5 years. Patients with NSIP pattern had significantly worse survival than those with NSIP + OP or OP patterns $(p=0.009)$. Patients with SSAb-positive IPAF had significantly worse survival than those with other IPAF groups $(p=0.003)$ (Fig. 2). Univariate Cox analysis revealed SScAb-positive IPAF

Table 3 HRCT pattern, therapy and prognosis of study participants stratified by specific antibodies

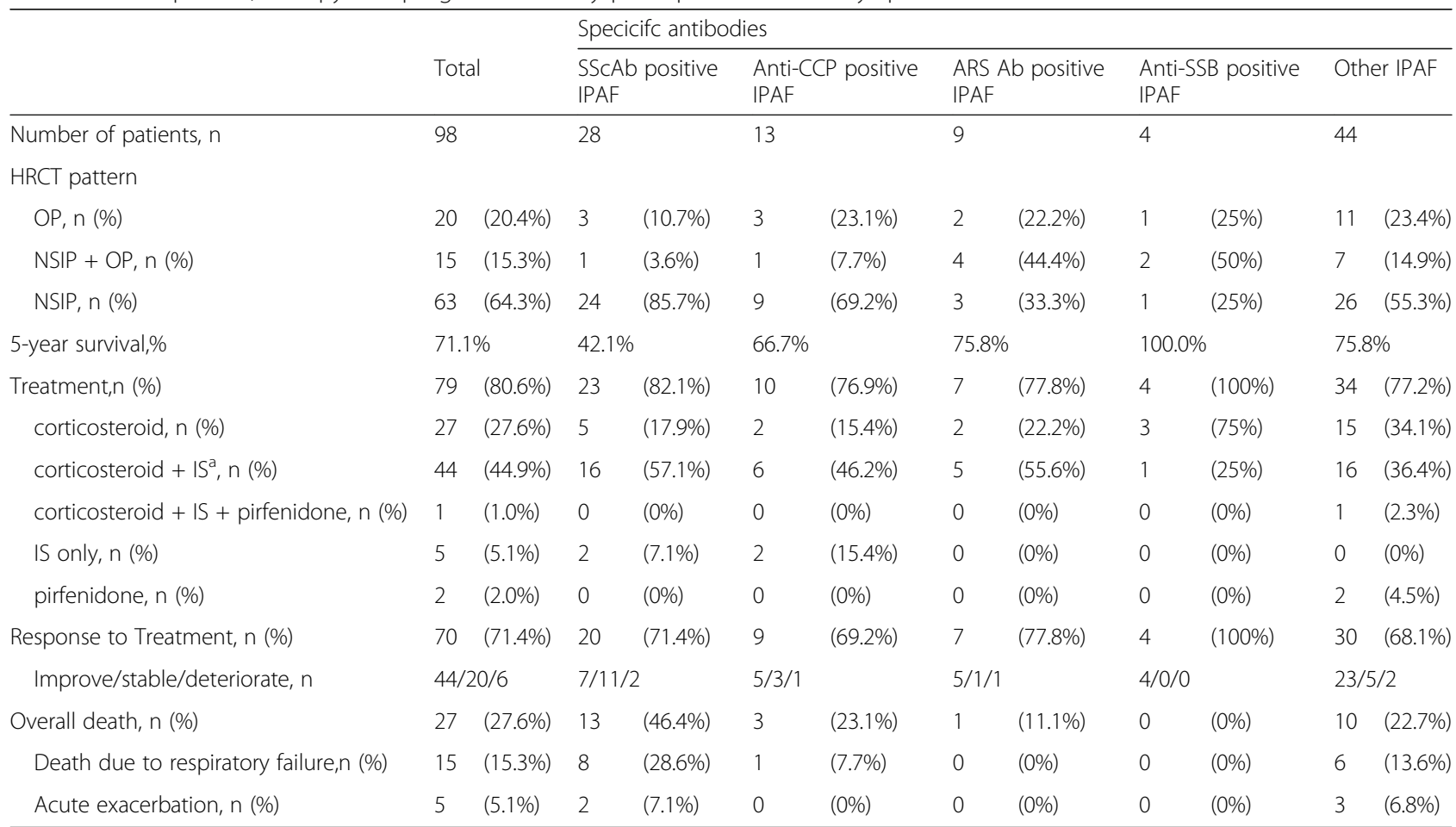

Data are presented as No.(\%). Anti-CCP uclic anti-citrullinated peptide, ARS Ab anti-tRNA synthetase antibodies, IPAF Interstitial pneumonia with autoimmune features, IS immnuno suppressants other than corticosteroid, NSIP non-specific interstitial pneumonia, NSIP + OP NSIP with OP overlap, OP organizing penumonia, SSCAb SSc-specific and SSc-related antibodies. ${ }^{a}$ IS = immnuno suppressants other than corticosteroid which included azathioprine, cyclsporin, cyclophosphamide and tacrolimus 

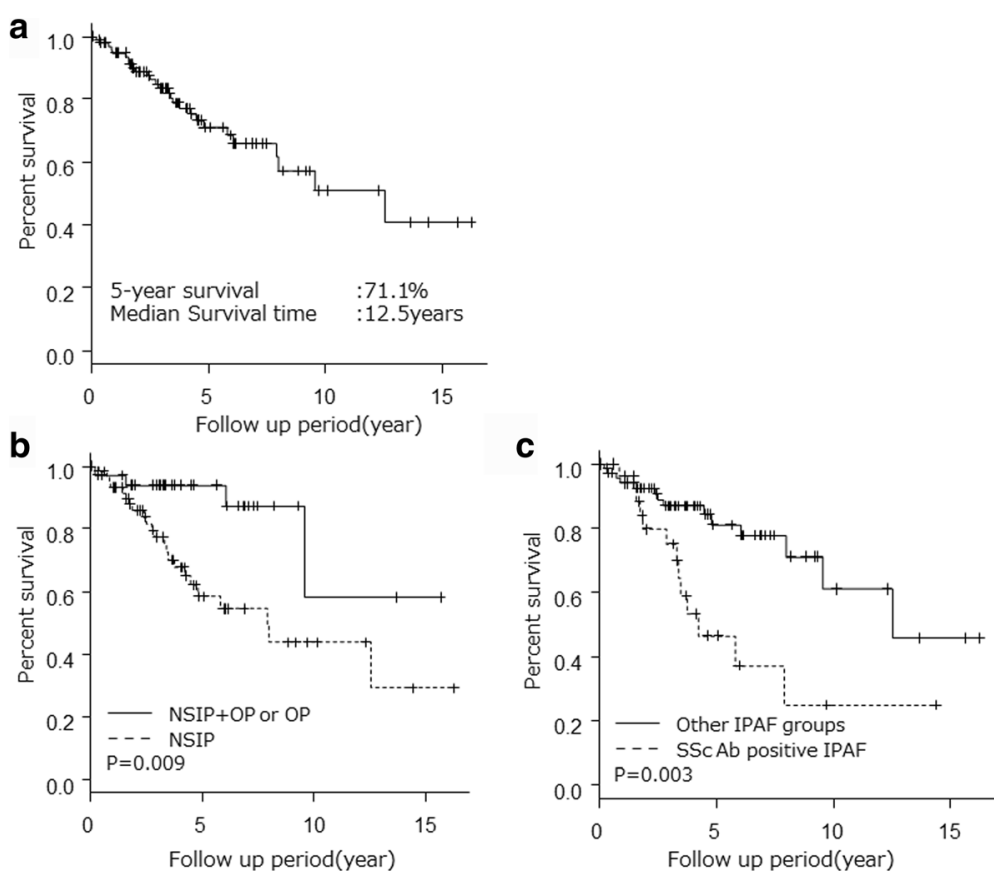

Fig. 2 Comparison of the survival curves of patients with IPAF. a Survival of patients with IPAF; b Survival of patients with NSIP + OP or OP and NSIP; c Survival of patients with SSCAb-positive IPAF and the other IPAF groups. The other IPAF goups included patients with Anti-CCP positive, ARS Ab positive, Anti-SSB positive IPAF and other IPAF. Anti-CCP = anti-cyclic citrullinated peptide; ARS Ab = anti-tRNA synthetase antibodies; IPAF = Interstitial pneumonia with autoimmune features; NSIP = non-specific interstitial pneumonia; $\mathrm{OP}=$ organizing pneumonia; NSIP + OP = NSIP with OP overlap; SscAb = SSc-related antibody

(hazard ratio [HR], 2.88; 95\% CI, $1.36-6.11 ; p=0.01$ ), radiological NSIP pattern (HR, 4.00; 95\% CI, 1.38-11.6, $p=0.01$ ), BAL fluid lymphocytes $>15 \%$ (HR, 0.29; $95 \%$ CI, $0.103-0.815, p=0.02$ ), and age (HR, 1.07; 95\% CI, $1.03-1.11, p<0.01)$ to be significant prognostic survival factors (Table 4). Multivariate Cox analysis revealed radiological NSIP pattern (HR, 4.48; 95\% CI, 1.2815.77, $p=0.02)$ and age (HR, 1.07; 95\% CI, 1.02-1.11, $p=0.01$ ) to be poor prognostic factors for survival (Table 5).

\section{Histopathological findings, characteristics, and outcomes of IPAF patients who underwent surgical lung biopsy} Seventeen patients (17.3\%) underwent SLB; 13 (20.6\%) with radiological NSIP, 3 (20.0\%) with NSIP + OP, and 1 (5\%) with OP pattern. Interstitial lymphoid aggregates with germinal centres were observed in 9 (52.9\%) patients, diffuse lymphoplasmacytic infiltration in 13 (76.5\%), and either of those features in 14 (82.4\%). Of the 13 patients presenting a radiological NSIP pattern, pathological diagnosis was NSIP in 8 , UIP in 3 , and unclassifiable in 2 patients. Of the 3 patients presenting a radiological NSIP + OP pattern, pathological diagnosis was also an NSIP + OP in 2, and NSIP in 1 patient. One patient presenting a radiological OP pattern also showed a OP pattern pathologically. Three patients presenting a radiological NSIP pattern and a pathological UIP pattern had relatively poor prognosis; two died due to respiratory failure during the follow-up period (34.5 and 30.5 months from the first visit respectively). On the other hand, amoung 8 patients with concordant NSIP pattern (i.e., radiological NSIP and a pathological NSIP pattern), 2 died during the follow-up period, and the median survival was 95.7 months (95\% CI, 69.8 months- not reached).

\section{Progression to CTD}

Twelve (12.2\%) of the 98 IPAF patients developed other characteristics and were diagnosed with CTD (rheumatoid arthritis (RA), $n=7$; systemic sclerosis, $n=2$; systemic lupus erythematosus, $n=1$; Sjogren's syndrome and systemic sclerosis, $n=1$; and dermatomyositis and systemic sclerosis, $n=1$ ) later during the median followup of 4.5 years (range: $1.88-6.07$ years; Table 6). Six patients $(9.5 \%)$ presenting with a radiological NSIP pattern were diagnosed with CTD later. Two patients (13.3\%) presenting with an NSIP + OP pattern were diagnosed with CTD later. Four patients $(20 \%)$ presenting with an OP pattern were diagnosed with CTD later.

\section{Discussion}

We confirmed here that radiological NSIP pattern and age are poor prognostic factors for survival in patients 
Table 4 Prognostic survival factors in patients with IPAF using univariate cox model

\begin{tabular}{lllll}
\hline & Number & HR & {$[95 \% \mathrm{Cl}]$} & $p$ value \\
\hline Age & 98 & 1.07 & {$[1.03-1.11]$} & $<0.01$ \\
Male sex & 98 & 1.98 & {$[0.92-4.25]$} & 0.08 \\
Smoker & 98 & 1.27 & {$[0.59-2.73]$} & 0.54 \\
Radiologic NSIP pattern vs. & 98 & 4.00 & {$[1.38-11.6]$} & 0.01 \\
NSIP + OP or OP pattern & & & & \\
SSCAb positive IPAF & 98 & 2.88 & {$[1.36-6.11]$} & 0.01 \\
Anti-CCP positive IPAF & 98 & 0.87 & {$[0.26-2.91]$} & 0.82 \\
Anti-SSB positive IPAF & 98 & NE & & 1.00 \\
ARS Ab positive IPAF & 98 & 0.25 & {$[0.03-1.89]$} & 0.18 \\
BAL fluid Lymphocytes $>15 \%$ & 75 & 0.29 & {$[0.10-0.82]$} & 0.02 \\
BAL fluid neutrophil > 3\% & 75 & 1.99 & {$[0.65-6.06]$} & 0.23 \\
BAL fluid eosinophil > 1\% & 75 & 0.63 & {$[0.25-1.59]$} & 0.33 \\
FVC\%predicted & 85 & 0.98 & {$[0.96-1.00]$} & 0.08 \\
DLCO\%predicted & 85 & 0.99 & {$[0.97-1.02]$} & 0.55 \\
\hline
\end{tabular}

Anti-CCP uclic anti-citrullinated peptide, $A R S A b$ anti-tRS antibody, $B A L$ bronchoalveolar lavage, $C l$ confidence interval, $D L C O$ diffusing capacity of the lung for carbon monoxide, FVC forced vital capacity, IPAF Interstitial pneumonia with autoimmune features, NE not evaluable, NSIP non-specific interstitial pneumonia, $N S I P+O P$ NSIP with OP overlap, OP organizing penumonia, SScAb SSc-specific and SSc-related antibodies

with IPAF patients who meet serological and morphological domain.

Univariate Cox analysis revealed radiological NSIP pattern, age, BAL fluid lymphocytes $>15 \%$, and SScAbpositive IPAF to be significant prognostic survival factors. First, the fact that radiological NSIP pattern is a poor prognostic factor for survival has been previously reported in cases of patients with IIP wherein the prognosis of patients with cryptogenic organizing pneumonia (COP) was better than those with NSIP. Nagai et al. compared the prognosis of 31 patients with idiopathic NSIP (iNSIP) with 16 COP patients. While no COP patient died or worsened, 2 iNSIP patients died and 3 worsened. They concluded that the prognosis of COP patients was better than that of iNSIP patients [3]. In this study, $13(20.6 \%)$ patients with radiological NSIP pattern underwent surgical lung biopsy, and 3 showed UIP pattern pathologically. In patients with IIP and CTD-ILD, the discordance between radiological and pathological diagnosis is also reported in previous

Table 5 Prognostic survival factors in patients with IPAF using multivariate cox model

\begin{tabular}{lllll}
\hline & $\mathrm{n}$ & $\mathrm{HR}$ & {$[95 \% \mathrm{CI}]$} & $p$ value \\
\hline Radiologic NSIP pattern vs. & 98 & 4.48 & {$[1.28-15.77]$} & 0.02 \\
NSIP + OP or OP pattern & & & & \\
Age & 98 & 1.07 & {$[1.02-1.12]$} & 0.01 \\
\hline
\end{tabular}

Cl confidence interval, NSIP non-specific interstitial pneumonia, NSIP + OP NSIP with OP overlap, $O P$ organizing penumonia
Table 6 Characteristics of patients with IPAF who progressed to connective tissue disease

\begin{tabular}{lllll}
\hline Number & CTD & Duration (month) & Specific antibody & HRCT pattern \\
\hline 1 & RA & 62.2 & $\begin{array}{l}\text { Anti-RNP, } \\
\text { anti-CCP }\end{array}$ & NSIP + OP \\
2 & SS + SSC & 88.2 & Anti-La/SSB & NSIP + OP \\
3 & RA & 10.7 & Anti-CCP & OP \\
4 & RA & 3.4 & Anti-CCP & OP \\
5 & RA & 20.3 & Anti-CCP & OP \\
6 & RA & 24.5 & Anti-CCP & NSIP \\
7 & RA & 32.8 & Anti-CCP & NSIP \\
8 & SSC + DM & 29.5 & Anti-RNP & NSIP \\
9 & SSC & 60.1 & Anti-SCl-70 & NSIP \\
10 & SLE & 26.3 & not detected & OP \\
11 & SSC & 56.4 & not detected & NSIP \\
12 & RA & 130.3 & not detected & NSIP
\end{tabular}

Anti-CCP anti-cyclic citrullinated peptide, Anti-RNP anti ribonucleoprotein, Anti-Scl-70 anti-Sclero 70, CTD connective tissue disease, DM dermatomyositis, NSIP non-specific interstitial pneumonia, NSIP + OP NSIP with OP overlap, OP organizing penumonia, RA Rheumatoid arthritis, SLE systemic lupus erythematosus, SS sjogren syndrome, SSC Systemic sclerosis

studies. Patients with concordant UIP had the highest mortality, while concordant NSIP had the lowest mortality. Discordant NSIP (i.e., radiological diagnosis of UIP or indeterminate, with histological diagnosis of NSIP) and discordant UIP (i.e., radiological diagnosis of NSIP or indeterminate, with histological diagnosis of UIP) were associated with lower mortality than those with concordant UIP, but greater mortality than those with concordant NSIP $[20,21]$. Three patients with discordant UIP may have influenced our result that radiological NSIP pattern had poor prognosis compared with NSIP + OP and OP pattern. In patients with radiological NSIP pattern, surgical lung biopsy should be considered to predict prognosis accurately, if possible. Furthermore, in the current study, differences and trends in disease onset, CRP, BAL findings, and KL6 among IPAF patients stratified according to HRCT were similar to those with IIPs, suggesting a similarity in the characteristics of IPAF and IIPs. Second, SScAb-positive IPAF was a significant poor prognostic factor for survival. This poor prognosis of patients with SScAb-positive IPAF might be mainly due to the lower frequency of good prognostic OP pattern. Among patients with SScAb-positive IPAF, good prognostic OP pattern was seen only in $3(12 \%)$ patients. In this study, anti-CCP-positive IPAF was not a significant prognostic survival factor. In contrast to other types of CTD, the reported prognosis of RA-ILD was relatively worse [22-24]. Park et al. reported that the survival of RA-ILD patients was not significantly worse than that of patients with other-non RA-CTD-ILD. However, using Kaplan-Meier survival analysis, they also reported that 
the survival of RA-UIP patients was similar to that of IPF/UIP patients and significantly worse than that of non-RA-CTD-UIP patients [6]. As these reports suggested, in RA patients, UIP pattern is often identified and thought to be a poor prognostic factor. In this study, although UIP pattern was often identified in patients with anti-CCP-positive IIP, all these patients could not be diagnosed with IPAF and thus were excluded. This might be partly the reason why anti-CCP-positive IIP was not a prognostic survival factor. Third, BAL fluid lymphocytes $>15 \%$ was a significant favourable prognostic survival factor. Patients with BAL lymphocytes $>15 \%$ might have a favourable prognostic pathological pattern. In a previous report, the average BAL fluid lymphocytes count was $37.3 \%, 44 \%$, and $7.2 \%$ in patients with iNSIP, COP, and IPF, respectively [3]. Another study reported that the average BAL fluid lymphocytes count was $40.5 \%, 19 \%$, and $5.5 \%$ in patients with cellular NSIP, fibrotic NSIP, and IPF. BAL fluid lymphocytosis was a significant favourable prognostic factor in those with fibrotic interstitial pneumonia [25].

Multivariate Cox analysis revealed radiological NSIP pattern and age as independent poor prognostic survival factors. Testing positive for SScAb was a significant poor prognostic survival factor in univariate analysis, but not in multivariate analysis. This suggested that compared to radiological-pathological patterns the autoantibodies that are highly specific for certain CTDs are less important in the prognosis of IPAF. Since CTD is a systemic disease, the prognosis of CTD-ILD may also be affected by organ dysfunctions other than ILD. For example, pulmonary arterial hypertension, chronic kidney disease and interstitial lung disease were reported to be the poor prognostic survival factors of SSc patients [26]. On the other hand, lung manifestation was usually the sole organ dysfunction in IPAF patients, and the prognosis might be more strongly affected by lung manifestation itself than the other organ dysfunction associated with each specific antibodies. In this study, age is also an independent poor prognostic survival factor independent of HRCT pattern. This result might have just represented life expectancy unrelated to the interstitial lung disease iteself as older patients have a shorter expected life-span.

In this analysis, 3 important findings suggested that IPAF was a lung-dominant variant of CTD or a CTD preceded by interstitial pneumonia. First, $12(12.2 \%)$ of the 98 IPAF patients later developed CTD. Fischer et al. reported that 3 of 74 patients who were positive for anti-CCP but not RA-ILD later developed RA [27]. Lee et al. reported that 3 of 18 biopsy-proven RA-ILD patients were not diagnosed with RA at first but later developed RA [6]. Bauer et al. reported that among 19 SSc-ILD patients, ILD occurred usually after the diagnosis of SSc in 16 patients but ILD occurred beforehand in 3 patients [26]. These reports suggest that some patients presented with ILD before being diagnosed with CTD. Pereira DA et al. reported that amoung 52 patients with lung-dominant CTD, 8 developed CTD later during the median follow up of 48 months [28]. In contrast, Chartrand et al. reported that amoung 56 patients with IPAF, none developed CTD later during the median follow up of 284.9 weeks [29]. One possible reason for these differences might be the diversity of the proportion of suggested CTD according to the diagnostic criteria in each cohort (e.g. positive rates of specific antibodies corresponding to each CTD may be different in each cohort). Further studies are needed to investigate this issue. However, the relatively high proportion of IPAF patients who developed CTD later in this study suggests the importance of longitudinal surveillance for evolution to CTD among those with IPAF and those with IIP in general. Second, of the 17 patients who underwent SLB, interstitial lymphoid aggregates with germinal centres and diffuse lymphoplasmacytic infiltration were frequently seen. These 2 histological findings are considered to be highly associated with CTD [16]. Omote et al. reported that among 44 patients with serologically positive lung-dominant CTD, interstitial lymphoid aggregates with germinal centres were observed in $21 \mathrm{pa}$ tients $(48 \%)$ and diffuse lymphoplasmacytic infiltration was observed in 32 (73\%) [30]. Song et al. reported that cases of IPF/UIP with positive autoantibodies had more characteristic histological features, such as germinal centres and plasma cells than did those of IPF/UIP without autoantibodies [31]. Third, HRCT patterns of IPAF patients stratified according to specific antibodies were similar to those of corresponding CTDs. In this study, patients with SScAb-positive IPAF showed a higher frequency of NSIP pattern than OP pattern. Previous reports showed that in patients with SSc, NSIP was frequently seen while OP was rare pathologically [32-34].

When we found patients with interstitial pneumonia to be positive with specific antibodies suggestive of an underlying CTD, we first administered immunosuppressive therapy. It is very important to identify the underlying cause in patients with ILD before diagnosing them with IIP as underlying causes help determine treatment principles. As this study and previous studies have shown, the IPAF criteria might be useful in identifying ILD patients suspected to have an underlying CTD. It is also reasonable to treat those IPAF patients with immunosuppressive treatments that are effective for certain suspected CTDs according to the specific antibodies.

This study has some limitations. First, we investigated only IPAF patients who satisfied the serological and morphological domains of the IPAF criteria. We did not investigate those who met the clinical and morphological 
domains. We excluded one patient who met the serological and clinical domains, although this subset seemed to be comparatively rare. Second, this was a retrospective single-centre study with a small sample size.

\section{Conclusions}

We confirmed that radiological NSIP pattern and age are significant poor prognostic factors for the survival of IPAF patients. This study suggested that the autoantibodies that are highly specific for certain CTDs might be less important for the prognosis of IPAF compared with the radiological-pathological patterns. The relatively high proportion of IPAF patients who developed CTD later suggests the importance of careful observation for evolution to CTD in IPAF.

\begin{abstract}
Abbreviations
anti-RA: anti-tRNA synthetase; ATS: American Thoracic Society; BAL: bronchoalveolar lavage; CCP: anti-cyclic citrullinated peptide; Cl: confidence interval; CTD: connective tissue disease; DLCO: diffusing capacity for carbon monoxide; ERS: European Respiratory Society; HR: hazard ratio; HRCT: high-resolution computed tomography; IIP: idiopathic interstitial pneumonia; ILD: nterstitial lung disease; iNSIP: idiopathic NSIP; IPAF: Interstitial pneumonia with autoimmune features; IPF: idiopathic pulmonary fibrosis; Jo1: anti-Jo1 antibody; NSIP: non-specific interstitial pneumonia; OP: organizing pneumonia; RA: rheumatoid arthritis; SLB: surgical lung biopsy; SSc: systemic sclerosis; SScAb: SSc-specific and SSc-associated antibodies; UIP: usual interstitial pneumonia
\end{abstract}

\section{Acknowledgements}

None.

\section{Ethics approval and consent participate}

This study protocol was approved by the ethics committee of Kurashiki Central Hospital in accordance with the Declaration of Helsinki (approval number 2143)

\section{Funding}

None.

\section{Availability of data and materials}

The datasets during and/or analysed during the current study available from the corresponding author on reasonable request. Identifying/confidential patient data cannot not be shared.

\section{Author's contributions}

YI, MA, SK, MN, FT, RT, KN, TK and IT designed this study and were involved in the acquisition of the data. YI, MA and SK analysed the data. YI wrote the manuscript. All authors approved the final version of the manuscript.

\section{Consent for publication}

Not applicable.

\section{Competing interests}

All authors declare they have no competing interests.

\section{Publisher's Note}

Springer Nature remains neutral with regard to jurisdictional claims in published maps and institutional affiliations.

\section{Author details}

'Department of Respiratory Medicine, Kurashiki Central Hospital, Kurashiki, Japan. ${ }^{2}$ Department of Endocrinology and Rheumatology, Kurashiki Central Hospital, Kurashiki, Japan. ${ }^{3}$ Department of Radiology, Kurashiki Central Hospital, Kurashiki, Japan. ${ }^{4}$ Department of Pathology, Kurashiki Central Hospital, Kurashiki, Japan.
Received: 29 January 2017 Accepted: 31 July 2017

Published online: 14 August 2017

\section{References}

1. Bjoraker JA, Ryu JH, Edwin MK, Myers JL, Tazelaar HD, Schroeder DR, Offord KP. Prognostic significance of histopathologic subsets in idiopathic pulmonary fibrosis. Am J Respir Crit Care Med. 1998;157:199-203.

2. Travis WD, Matsui K, Moss J, Ferrans VJ. Idiopathic nonspecific interstitial pneumonia: prognostic significance of cellular and fibrosing patterns: survival comparison with usual interstitial pneumonia and desquamative interstitial pneumonia. Am J Surg Pathol. 2000;24:19.

3. Nagai S, Kitaichi M, Itoh H, Nishimura K, Izumi T, Colby TV. Idiopathic nonspecific interstitial pneumonia/fibrosis: comparison with idiopathic pulmonary fibrosis and BOOP. Eur Respir J. 1998;12:1010-9.

4. Nicholson AG, Colby TV, du Bois RM, Hansell DM, Wells AU. The prognostic significance of the histologic pattern of interstitial pneumonia in patients presenting with the clinical entity of cryptogenic fibrosing alveolitis. Am J Respir Crit Care Med. 2000;162:2213-7.

5. Park JH, Kim DS, Park IN, Jang SJ, Kitaichi M, Nicholson AG, Colby TV. Prognosis of fibrotic interstitial pneumonia: idiopathic versus collagen vascular diseaserelated subtypes. Am J Respir Crit Care Med. 2007;175:705-11.

6. Lee HK, Kim DS, Yoo B, Seo JB, Rho JY, Colby TV, Kitaichi M. Histopathologic pattern and clinical features of rheumatoid arthritis-associated interstitial lung disease. Chest. 2005;127:2019-27.

7. Nakamura Y, Suda T, Kaida Y, Kono M, Hozumi H, Hashimoto D, Enomoto N, Fujisawa T, Inui N, Imokawa S, Yasuda S, Shirai T, Suganuma H, Morita S, Hayakawa H, Takehara Y, Colby TV, Chida K. Rheumatoid lung disease: prognostic analysis of 54 biopsy-proven cases. Respir Med. 2012;106:1164-9.

8. Van den Hoogen F, Khanna D, Fransen J, Johnson SR, Baron M, Tyndall A, Cerinic MM, Naden RP, Medsger TA Jr, Carreira PE, Riemekasten G, Clements PJ, Denton CP, Distler O, Allanore Y, Furst DE, Gabrielli A, Mayes MD, van Laar JM, Seibold JR, Czirjak L, Steen VD, Inanc M, Kowal-Bielecka O, MüllerLadner U, Valentini G, Veale DJ, Vonk MC, Walker UA, Chung L, Collier DH, Csuka ME, Fessler BJ, Guiducci S, Herrick A, Hsu VM, Jimenez S, Kahaleh B, Merkel PA, Sierakowski S, Silver RM, Simms RW, Varga J, Pope JE. 2013 classification criteria for systemic sclerosis: an American college of rheumatology/European league against rheumatism collaborative initiative. Ann Rheum Dis. 2013;72:1747-55.

9. Aletaha D, Neogi T, Silman AJ, Funovits J, Felson DT, Bingham CO III, Birnbaum NS, Burmester GR, Bykerk VP, Cohen MD, Combe B, Costenbader $\mathrm{KH}$, Dougados M, Emery P, Ferraccioli G, JMW H, Hobbs K, TWJ H, Kavanaugh A, Kay J, Kvien TK, Laing T, Mease P, Ménard HA, Moreland LW, Naden RL, Pincus T, Smolen JS, Stanislawska-Biernat E, Symmons D, Tak PP, Upchurch KS, Vencovsky J, Wolfe F, Hawker G. 2010 rheumatoid arthritis classification criteria: an American College of Rheumatology/European League Against Rheumatism collaborative initiative. Ann Rheum Dis. 2010;69:1580-8

10. Bohan A, Peter JB. Polymyositis and dermatomyositis. N Engl J Med. 1975;292:344-7.

11. Vitali C, Bombardieri S, Jonsson R, Moutsopoulos HM, Alexander EL, Carsons SE, Daniels TE, Fox PC, Fox Rl, Kassan SS, Pillemer SR, Talal N. Weisman MW, and the European study group on classification criteria for Sjögren's syndrome. Classification criteria for Sjögren's syndrome: a revised version of the European criteria proposed by the American-European Consensus Group. Ann Rheum Dis. 2002;61:554-8.

12. Tan EM, Cohen AS, Fries JF, Masi AT, McShane DJ, Rothfield NF, Schaller JG, Talal N, Winchester RJ. The 1982 revised criteria for the classification of systemic lupus erythematosus. Arthritis Rheum. 1982;25:1271-7.

13. Smolen JS, Steiner G. Mixed connective tissue disease: to be or not to be? Arthritis Rheum. 1998;41:768-77.

14. Raghu G, Collard HR, Egan JJ, Martinez FJ, Behr J, Brown KK, Colby TV, Cordier JF, Flaherty KR, Lasky JA, Lynch DA, Ryu JH, Swigris JJ, Wells AU, Ancochea J, Bouros D, Carvalho C, Costabel U, Ebina M, Hansell DM, Johkoh T, Kim DS, King TE Jr, Kondoh Y, Myers J, Müller NL, Nicholson AG, Richeldi L, Selman M, Dudden RF, Griss BS, Protzko SL, Schünemann HJ. ATS/ERS/ JRS/ALAT committee on idiopathic pulmonary fibrosis. Am J Respir Crit Care Med. 2011;183:788-824.

15. Travis WD, Costabel U, Hansell DM, King TE Jr, Lynch DA, Nicholson AG, Ryerson CJ, Ryu JH, Selman M, Wells AU, Behr J, Bouros D, Brown KK, Colby TV, Collard HR, Cordeiro CR, Cottin V, Crestani B, Drent M, Dudden RF, Egan J, Flaherty K, Hogaboam C, Inoue Y, Johkoh T, Kim DS, Kitaichi M, Loyd J, 
Martinez FJ, Myers J, Protzko S, Raghu G, Richeldi L, Sverzellati N, Swigris J, Valeyre D. An official American Thoracic Society/European Respiratory Society statement: Update of the international multidisciplinary classification of the idiopathic interstitial pneumonias. Am J Respir Crit Care Med. 2013;188:733-48

16. Fischer A, Antoniou KM, Brown KK, Cadranel J, Corte TJ, du Bois RM, Lee JS, Leslie KO, Lynch DA, Matteson EL, Mosca M, Noth I, Richeldi L, Strek ME, Swigris JJ, Wells AU, West SG, Collard HR, Cottin V. An official European Respiratory Society/American Thoracic Society research statement: interstitial pneumonia with autoimmune features. Eur Respir J. 2015:46:976-87.

17. Miller MR, Hankinson J, Brusasco V, Burgos F, Casaburi R, Coates A, Crapo R, Enright P, van der Grinten CPM, Gustafsson P, Jensen R, Johnson DC, Maclntyre N, McKay R, Navajas D, Pedersen OF, Pellegrino R, Viegi G, Wanger J. Standardisation of spirometry. Eur Respir J. 2005;26:319-38.

18. Macintyre N, Crapo RO, Viegi G, Johnson DC, van der Grinten CPM, Brusasco V, Burgos F, Casaburi R, Coates A, Enright P, Gustafsson P, Hankinson J, Jensen R, McKay R, Miller MR, Navajas D, Pedersen OF, Pellegrino R, Wanger J. Standardisation of the single-breath determination of carbon monoxide uptake in the lung. Eur Respir J. 2005;26:720-35.

19. Meyer KC, Raghu G, Baughman RP, Brown KK, Costabel U, du Bois RM, Drent M, Haslam PL, Kim DS, Nagai S, Rottoli P, Saltini C, Selman M, Strange C, Wood B. An official American Thoracic Society clinical practice guideline: the clinical utility of bronchoalveolar lavage cellular analysis in interstitial lung disease. Am J Respir Crit Care Med. 2012;185:1004-14.

20. Flaherty KR, Thwaite EL, Kazerooni EA, Gross BH, Toews GB, Colby TV, Travis WD, Mumford JA, Murray S, Flint A, Lynch JP 3rd, Martinez FJ. Radiological versus histological diagnosis in UIP and NSIP: survival implications. Thorax. 2003:58:143-8.

21. Walsh SL, Sverzellati N, Devaraj A, Keir GJ, Wells AU, Hansell DM. Connective tissue disease related fibrotic lung disease: high resolution computed tomographic and pulmonary function indices as prognostic determinants. Thorax. 2014;69:216-22.

22. Hakala M. Poor prognosis in patients with rheumatoid arthritis hospitalized for interstitial lung fibrosis. Chest. 1988;93:114-8.

23. Masanori A, Mitsunori $\mathrm{S}$, Hideki $\mathrm{H}$. Thin-section $\mathrm{CT}$ findings in rheumatoid arthritis-associated lung disease: CT patterns and their courses. J Comput Assist Tomogr. 1999;23:941-8.

24. Saravanan V, Kelly CA. Survival in fibrosing alveolitis associated with rheumatoid arthritis is better than cryptogenic fibrosing alveolitis. Rheumatology (Oxford). 2003;42:603-4.

25. Ryu YJ, Chung MP, Han J, Kim TS, Lee KS, Chun ES, Kyung SY, Jeong SH, Colby TV, Kim H, Kwon OJ. Bronchoalveolar lavage in fibrotic idiopathic interstitial pneumonias. Respir Med. 2007;101:655-60.

26. Bauer PR, Schiavo DN, Osborn TG, Levin DL, St Sauver J, Hanson AC, Schroeder DR, Ryu JH. Influence of interstitial lung disease on outcome in systemic sclerosis: a population-based historical cohort study. Chest. 2013;144:571-7.

27. Fischer A, Solomon JJ, du Bois RM, Deane KD, Olson AL, Fernandez-Perez ER, Huie TJ, Stevens AD, Gill MB, Rabinovitch AM, Lynch DA, Burns DA, Pineiro IS, Groshong SD, Duarte Achcar RD, Brown KK, Martin RJ, Swigris JJ. Lung disease with anti-CCP antibodies but not rheumatoid arthritis or connective tissue disease. Respir Med. 2012;106:1040-7.

28. Pereira DA, Dias OM, Almeida GE, Araujo MS, Kawano-Dourado LB, Baldi BG, Kairalla RA, Carvalho CR. Lung-dominant connective tissue disease among patients with interstitial lung disease: prevalence, functional stability, and common extrathoracic features. J Bras Pneumol. 2015;41:151-60.

29. Chartrand S, Swigris JJ, Stanchev L, Lee JS, Brown KK, Fischer A. Clinical features and natural history of interstitial pneumonia with autoimmune features: a single center experience. Respir Med. 2016;119:150-4.

30. Omote N, Taniguchi H, Kondoh Y, Watanabe N, Sakamoto K, Kimura T, Kataoka K, Johkoh T, Fujimoto K, Fukuoka J, Otani K, Nishiyama O, Hasegawa Y. Lung-dominant connective tissue disease: clinical, radiologic, and histologic features. Chest. 2015;148:1438-46.

31. Song JW, Do KH, Kim MY, Jang SJ, Colby TV, Kim DS. Pathologic and radiologic differences between idiopathic and collagen vascular diseaserelated usual interstitial pneumonia. Chest. 2009;136:23-30.

32. Bouros D, Wells AU, Nicholson AG, Colby TV, Polychronopoulos V, Pantelidis P, Haslam PL, Vassilakis DA, Black CM, du Bois RM. Histopathologic subsets of fibrosing alveolitis in patients with systemic sclerosis and their relationship to outcome. Am J Respir Crit Care Med. 2002;165:1581-6.
33. Fujita J, Yoshinouchi T, Ohtsuki Y, Tokuda M, Yang Y, Yamadori I, Bandoh S, Ishida T, Takahara J, Ueda R. Non-specific interstitial pneumonia as pulmonary involvement of systemic sclerosis. Ann Rheum Dis. 2001;60:281-3.

34. Kim DS, Yoo B, Lee JS, Kim EK, Lim CM, Lee SD, Koh Y, Kim WS, Kim WD, Colby TV, Kitiaichi M. The major histopathologic pattern of pulmonary fibrosis in scleroderma is nonspecific interstitial pneumonia. Sarcoidosis Vasc Diffuse Lung Dis. 2002;19:121-7.

\section{Submit your next manuscript to BioMed Central and we will help you at every step:}

- We accept pre-submission inquiries

- Our selector tool helps you to find the most relevant journal

- We provide round the clock customer support

- Convenient online submission

- Thorough peer review

- Inclusion in PubMed and all major indexing services

- Maximum visibility for your research

Submit your manuscript at www.biomedcentral.com/submit
Biomed Central 